\title{
What's in a Name?
}

I work at the University of Chicago, "The Forefront of Medicine." I'm not sure who came up with that slogan but it seems ubiquitous in our ad campaigns. Some of our competitors like to change the word "forefront" to "fore-", well...you can figure it out. As I'm sitting here typing and watching the Cubs middle relief blow yet another game, I just saw one of our new ads on TV. This one shows the new outpatient center and the narrator says, "The University of Chicago Hospitals, where answers are found." Hmm, OK. This sounds pretty dramatic and I'm sure some ad exec who is paid better than I am came up with the catchphrase. When you think about it, I guess it is pretty good. It is technically accurate, it doesn't promise the "answers" will be positive. The word "solution" isn't used either. One of our radiology residents is used in the ad-he looks very thoughtful and all but personally, I doubt he will be responsible for finding many answers, at least not until he completes his training.

In interventional radiology, we have discovered that names are important because no one outside the specialty really has a clue what we do. Then again, I think that changing professional names sometimes indicates an identity crisis. Once we were the Society of Cardiovascular and Interventional Radiology, now we are the Society of Interventional Radiology (or SIR). Some interventional radiologists call themselves "minimally invasive surgeons" or "image-guided surgeons." I think the term "pinhole surgeon" was fashionable for a short period of time but has fallen out of favor lately as "pinhole" is too close to "pinhead." When I use the term "pinhead surgeon," I'm usually not referring to an interventional radiologist. All these monikers are very descriptive and help the lay person understand what we do, although most are not entirely accurate. For one, we aren't surgeons in the conventional definition of the term. The vast majority of us have completed training in radiology, not surgery in the traditional sense. More- over, the holes I create are usually a lot bigger than pinholes - more like spaghetti holes or \#8 drywall screw holes. As a fan of Sergio Leone and Clint Eastwood, I personally would like to call myself a "spaghetti radiologist" but that doesn't exactly inspire confidence, does it?

Even surgeons are trying to reinvent themselves. It doesn't exactly take a nuclear physicist to figure out that bigger is not better to most people when you're talking about incisions and scars. So now we have the "Center for Minimally Invasive Techniques" run by our surgeons. They seem embarrassed about it when they are around interventional radiologists. I smugly asked one of our surgeons how that is different from what I do. $\mathrm{He}$ didn't have an answer for me. Not surprising. I also like to say to him, "This guy needs an operation, go find me a surgeon." He really enjoys that one.

The other day, we were placing a nephrostomy catheter in a very nervous patient. This was one of those procedures where everything went right from the transportation of the patient, to the preprocedure history and physical (now a requirement in my hospital), to the sedation, procedure, and recovery. Amazingly, this actually occurs in teaching hospitals occasionally. As he was being taken out of the interventional radiology suite, the patient was relieved and thrilled and excited all at the same time that everything went so well. He was profusely thanking our staff and remarked, "That was great. You guys really are the forefront of medicine!" Wow, I thought. Maybe these catch phrases really do work. Then again, I think our patient actually believed the slogan for only 15 seconds or so. I suspect he changed his mind when the technologist who was entering the procedure in our computer system stuck his head around the corner and asked, "Is kidney spelled with a $y$ or an $i e$ ?"

Brian Funaki, M.D. Editor in Chief ${ }^{1}$

Transjugular Intrahepatic Portosystemic Shunts: An Update; Editors in Chief, Brian Funaki, M.D., Peter R. Mueller, M.D.; Guest Editor, Hector Ferral, M.D. Seminars in Interventional Radiology, volume 22, number 4, 2005. Address for correspondence and reprint requests: Brian Funaki, M.D., Section of Vascular and Interventional Radiology, University of Chicago Hospitals, 5840 S. Maryland Avenue, MC 2026, Chicago, IL 60637. ${ }^{1}$ Section of Vascular and Interventional Radiology, University of Chicago Hospitals, Chicago, Illinois. Copyright (C) 2005 by Thieme Medical Publishers, Inc., 333 Seventh Avenue, New York, NY 10001, USA. Tel: +1(212) 584-4662. 0739-9529,p;2005,22,04,251,252,ftx,en; sir00324a. 